\title{
Original article (full paper) \\ Space protection dynamics in basketball: Validation and application to the evaluation of offense-defense patterns
}

\author{
Felipe L. Santana \\ University of São Paulo, São Paulo, SP, Brazil \\ Eduardo Rostaiser \\ German Sport University Cologne, Cologne, Germany \\ Eran Sherzer \\ Paulistano Athletic Club, São Paulo, SP, Brazil \\ Carlos Ugrinowitsch \\ Junior Barrera \\ University of São Paulo, São Paulo, SP, Brazil \\ Leonardo Lamas \\ University of Brasilia, Brasília, DF, Brazil
}

\begin{abstract}
The aims of this study were twofold: i) to validate classes of defensive actions (i.e., space protection dynamics - SPDs) for containing offense in basketball; and ii) to propose a novel approach to analyze matches based on the interaction of a space creation dynamic (SCD) and a respective SPD. Kappa statistics revealed high intra- and inter-raters values, supporting the reliability of the defined SPDs. Six matches of the Spanish professional basketball finals were analyzed to achieve the second purpose of the present study. The SCD-SPD couples of actions were analyzed regarding their frequency of occurrence and variety until a scoring attempt. Teams' utilization of sequences of SCDs and SPDs was similar and short in length. Additionally, combining a second action with the first seemed to positively impact on offense success. The analysis of SCDs-SPDs interactions comprehend an innovative approach to the tactical evaluation of matches and may be helpful to interpret teams playing patterns.
\end{abstract}

Keywords: strategy, tactical patterns, performance analysis, teams' interactions

Resumo - "Dinâmicas de proteção do espaço no basquetebol: validação e aplicação para a avaliação de padrões ataquedefesa." O estudo teve dois objetivos: i) validar classes de ações defensivas para contenção do ataque no basquetebol (i.e. dinâmicas de proteção de espaço - DPEs); ii) propor uma nova abordagem para analisar partidas de basquetebol baseada nas interações entre uma dinâmica de criação de espaço (DCE) e a respectiva DPE. A estatística Kappa revelou elevada concordância intra- e inter avaliadores, confirmando a reprodutibilidade das DPEs definidas. Seis partidas das finais do campeonato espanhol de basquetebol foram analisadas. DCEs-DPEs foram analisadas quanto a sua frequência de ocorrência e diversidade de ações até a realização de uma finalização. A utilização de DCEs-DPEs foi semelhante entre as equipes e de pequeno comprimento. Além disso, a combinação de uma segunda ação com a primeira pareceu ter um impacto positivo no sucesso do ataque. A análise das interações entre DCEs-DPEs constitui uma abordagem inovadora para a avaliação tática das partidas e pode contribuir para a interpretação dos padrões de jogo das equipes.

Palavras-chave: estratégia, padrões táticos, análise de desempenho, interação

Resumen - "Dinámicas de protección del espacio en el baloncesto: validación e aplicación para evaluación de patrones ataque-defensa." Los objetivos del presente estudio fueron dos: i) validar clases de acciones defensivas para contención ofensiva en baloncesto (i.e. dinámicas de protección del espacio - DPEs); y ii) proponer un nuevo abordaje para analizar partidos de baloncesto basado en la interacción entre una dinámica de creación del espacio (DCE) y una respectiva DPE. La estadística Kappa reveló grande concordancia intra- e inter-evaluadores, confirmando la reproductibilidad de las DPEs. Seis partidos de las finales del campeonato de baloncesto de España fueron analizadas para alcanzar el segundo objetivo del presente estudio. Los pares de acción DCE-DPE fueron analizados cuanto a la frecuencia de ocurrencia y 
variedad hasta el momento de la finalización. La utilización de DCEs-DPEs por los equipos fue similar y con secuencias cortas. Además, una segunda acción combinada con la primera pareció tener un impacto positivo en el éxito del ataque. El análisis de la interacción DCEs-DPEs consiste un abordaje innovador para la evaluación táctica de los partidos y puede contribuir para interpretar patrones de juego.

Palabras claves: estrategia, patrones tácticos, análisis del rendimiento, interacciones

\section{Introduction}

In a basketball match, defensive and offensive teams organize their plays to minimize scoring opportunities of the adversary and to maximize the chances of scoring points, respectively. A coach conceives each team play as a sequence of interconnected individual actions aiming at supporting the collective performance. The set of planned sequences of interconnected actions (i.e., team plays) defines a team strategy (Lamas, Barrera, Otranto, \& Ugrinowitsch, 2014), which seems to be a determinant factor of team success in a match (Collet, 2013).

Match analysts assess team strategy from tactical data (i.e., plays) gathered along several matches of the team. Then, the most recurrent plays can be identified and assumed as part of the team's strategy. In contrast, low-frequency plays are considered as part of occasional opposition circumstances. However, an analytical framework should be developed to consistently evaluate the sequence of actions that characterize a play.

Scientific evidences corroborate with this perspective and suggest the assessment of sequences of team actions instead of discrete variables focused on plays outcome only (Correia, Araújo, Vilar, \& Davids, 2013). In most of these studies, analyses performed have been capturing the result of displacements of the whole team (Collet, 2013; Grehaigne \& Caty, 2010; Pfeiffer, \& Perl, 2006; Seabra \& Dantas, 2006) . Analysis of information such as ball circulation and occupation areas in the match field aimed at identifying the most recurrent patterns. The relationship between the most recurrent tactical patterns, whose greater frequency may be attributed to their strategic nature, and related outcomes (e.g., score attempt, turnover) enables evaluating the efficiency of the team strategy (Grehaigne \& Caty, 2010; Seabra \& Dantas, 2006).

Studies dealing with the dynamical analyzes of a team's tactical patterns have not systematically addressed the players' actions that define the patterns of ball circulation and occupation of areas in the match field. The discrimination of the tactical meaning of the actions performed by the team players in the analyzed sequences of displacements can unravel how players organize the collective actions of the team, defining with high accuracy how an outcome was obtained. In this regard, Lamas et al. (2011) investigated the performance of small groups of players in basketball and proposed equivalence classes ${ }^{1}$ for the set of offensive actions players may perform. For instance, a pick was defined as an equivalence class for all actions involving two team players, in which player 1 obstructs the trajectory of the

\footnotetext{
${ }^{1}$ An equivalence class is a mathematical concept according to which when a set has an equivalence relation defined on its elements, there is a grouping of elements that are related to one another, forming an equivalence class.
}

defender of the player 2 (the ball player) to free his teammate. Space creation dynamics (SCDs) was the selected term to define these actions.

The SCDs, defined as equivalence classes, generalize all possible actions players may perform to create space in basketball offense. Consequently, any strategic specification a coach may design should use elements of this set of SCDs. In the tactical analysis of a match, among the annotated SCDs, those with greater recurrence may be related to the pre-defined strategy of the team. The possibility of assessing frequencies of SCDs provides greater accuracy in the interpretation of the reasons of the strategy efficiency than analysis based on general tactical patterns only (e.g., patterns of ball circulation).

To increase the resolution of basketball match analysis, not only the SCDs should be considered, but also the tactical meaning of their respective defensive actions. The development of observational methods encompassing sequences of both offensive and defensive behavioral patterns should lead to a better comprehension of the context in which players executed the team strategy and the reasons for the achievement of a given final result in the ball possession. This integrative perspective of offensive and defensive actions should extend the previous contributions of Lamas et al. (2011), providing indices of preferential patterns in terms of the number of actions in a sequence a team may use (i.e., shorter or longer sequences) and prefered actions in these sequences.

Therefore, the present study had two goals: i) to validate a set of classes of actions that can be strategically specified and tactically performed by defense to impair offense from creating space and scoring in basketball; ii) to apply these defensive classes and the SCDs to investigate sequences of actions along ball possessions in basketball.

\section{Methods}

\section{Approach to the problem}

Lamas et al. (2011) presented a set of basketball offensive classes corresponding to the possible offensive specifications to create space in the adversary defensive system, which leads to scoring opportunities, the SCDs. The logical corollary of the work developed by Lamas et al. (2011) is the definition of a set of actions that can be strategically specified to counteract the SCDs. Hence, the SCDs were used as a reference to conceive and validate their correspondent defensive classes, the space protection dynamics (SPDs). The Ethical Committee of the School of Physical Education and Sport of the University of Sao Paulo approved all experimental procedures (protocol: 2009-10). 
For simplicity sake, the SCDs were revisited and two of the original classes proposed by Lamas and colleagues (2011), one versus one situation in the perimeter, both with or without dribbles, were combined in one class. Then, the resultant offensive classes were the following: i) one versus one situation in the perimeter ${ }^{2}$; ii) one versus one situation in the post ${ }^{3}$; iii) on ball screens ${ }^{4}$; iv) space creation without the ball: iv ${ }_{\mathrm{a}}$ ) staying in open space (spot-up); $\mathrm{iv}_{\mathrm{b}}$ ) cutting for the open space (e.g., back-door cut, front-door cut); v) out of ball screens ${ }^{3}$. Reviewing the SCD classes was important to the process of developing and validating the SPDs as the defensive actions are usually reactive to the offensive actions during basketball matches.

After validating the SPDs, we analyzed basketball matches looking at the sequences of SCDs and SPDs that occurred in each ball possession up to a scoring attempt. Analyzing each SCD-SPD couple is important to unravel if a given SCD leads to a specific SPD and how the sequence of SCD-SPD couples unfolds up to the scoring attempt. The number of SCD-SPD couples performed up to a scoring attempt was assessed to determine the team preferences regarding how to disrupt the defensive system. For instance, counting the number of SCD-SPD couples enabled to analyze if very organized professional teams perform a high number of SCD-SPD couples up to a scoring attempt, as the team may attempt to create a clear space advantage.

\section{Validation process}

The validation of the SPDs followed a seven step approach, according to the guidelines presented by Fonseca, Salles, and Parente (2008): i) construction of a preliminary version of the instrument, founded on empirical experience of the researchers involved with the work, opinion of high-level coaches, and literature research; ii) blind judges' analyses: an analysis of the adequacy of the inclusion of each element in the instrument, considering the assessed construct and the instrument's goal; iii) reformulation of the instrument; iv) semantic analysis of the items; v) analysis of the instrument (i.e., three blinded specialists, other than those of step i, judge the instrument); vi) pilot study and final version, and vii) application. The seven steps to the validation of the SPDs are explained below:

First, we conducted the construction of a preliminary version of the set of SPDs considering the empirical knowledge of the researchers (six academics with more than 10 years of experience in match analysis investigations) and other two specialists in team sports match analysis, discussions with high-level basketball coaches and extensive review of the literature. Two criteria previously used to classify a certain behavior in one of the SCDs (Lamas et al., 2011) were applied for the preliminary classification of the defensive actions as a given SPD: i) the type of technical skill performed, which describes the chosen motor solution in a given context (e.g., the defense

\footnotetext{
${ }^{2}$ Perimeter designates the court area outside from the three-point line. ${ }^{3}$ Post designates the court painted area close to the basket, with a trapezoidal shape.

${ }^{4}$ Screen designates the action in which an offensive player obstructs the path of the defender of his teammate aiming to create space.
}

of 1 on 1 in the perimeter can involve an oriented to a side or a neutral positioning); ii) the number of players involved, which represents an objective measure of players inter-dependency in a given action (e.g., two defensive players guard the offensive action of a pick). Once we defined the set of SPDs, several match analysis experiments were performed to test the coherence of the conceived SPDs.

Second, the logic and accuracy of the criteria defining each SPD was evaluated through blind judges' analyzes. Judges were three high-level basketball coaches, with more than 15 years of experience in international basketball. Interestingly, even high-level basketball coaches were not well familiarized with the process of formally analyzing strategic-tactical contents. This circumstance led the authors to organize extensive video documentation to the analysis of concepts and criteria related to the SPDs. The procedure involved the selection of 70 defensive actions representative of the pre-defined SPDs. We obtained these defensive actions from 20 matches of the Olympic Games (2008) and World Championship (2010) basketball male tournaments. Each pre-defined SPD had at least three representative video-clips. Each video-clip comprised a complete ball possession in which arrows or circles indicated the players involved in the SPD of interest. SPDs were organized in a timeline and presented to the three high-level coaches, who blindly analyzed the video-clips. The reports provided by the high-level coaches included the assignment of a specific SPD for each action whose evaluation was required according to the indication in each video-clip. These assignments of SPDs to actions were used to improve SPD criteria in the subsequent step of the validation process.

Third, in the case a defensive action assigned in one of the video-clips did not suit one of the pre-defined SPDs this was pointed out by the high-level coaches, who also suggested the SPD that could contemplate the action. Assignments of each coach were compared with the ones of the other two coaches. Additionally, coaches' assignments were compared to the researchers' classification, which was performed based on the actions selected from matches to generate the video-clips. Reliability evaluation encompassed the agreements within the three high-level coaches and between high-level coaches and researchers for each video-clip. Multiple-rater analysis of reproducibility was applied to compare between raters (i.e., coaches and researchers) the similarity of the SPD assigned in each video-clip. Reliability ratios were evaluated according to the Landis and Koch (1977) levels of agreement for the Kappa value: $<0$ less than the chance agreement, .01 - .20 slight agreement, $.21-.40$ fair agreement, $.41-.60$ moderate agreement, $.61-.80$ substantial agreement and $.81-.99$ almost perfect agreement. Kappa coefficients $\leq .85$ of concordance within coaches or between coaches and researchers indicated the necessity to reformulate the classification criteria of that SPD. The analyzes of expert coaches resulted in modifications and additions in the criteria used to define the SPDs. Intra-rater reliability indicated almost perfect agreement, suggesting that each coach captured the conceptual relation between a SPD and the respective defining criteria. In relation to the researchers original classification, coaches' assignments varied between 
substantial and almost perfect agreement. Moreover, in most of the divergent cases between researchers and coaches, all three coaches converged in their assignments. The preliminary criteria (i.e., number of players involved; type of technical skill performed) were modified to: i) the SCD performed by offense, which defines the number of players involved in an offensive action and the respective number of players involved in the defensive action; ii) the relative body orientation (e.g. oriented defense in $1 x 1$ situation in the perimeter, see Table 1) or displacement performed by the defender in relation to the attacker (e.g., defensive action "show" against the offensive action "pick," see Table 1).

Fourth, researchers and coaches had another round of discussions to implement semantic corrections to the SPDs denomination, in the case of some divergence between the coaches regarding the terminology to classify the analyzed actions. For instance, pick was defined as the most appropriate term to describe the action that is alternatively denominated on ball screen, screen or pick (see Figure 1 for an illustration of the pick).

Fifth, another set of three experienced high-level basketball coaches than those of step i conducted a final analysis to guarantee the accuracy of the SPD defined criteria. Reliability estimates of SPDs' identification were performed as follow. First, the researcher drew a sample of 85 ball possessions from 996 ball possessions obtained from 12 matches. The matches were from the NBA conferences' final play-offs (2011), Euro-league's semi-finals (2011) and World Championship (2010) semi-finals. The 85 ball possessions were organized in a randomized video sequence, containing a similar number of actions for each of the SPDs. To identify the exact SPD of interest in each ball possession, a legend indicated the correspondent offensive class (i.e., SCD). Each coach performed a blind analysis of the SPDs in each ball possession. Coaches repeated the analysis on three different occasions, one week apart from each other, for wash -out purposes, and the results were used to evaluate intra- and inter-raters reliability. The plays were presented to the coaches in a random order between and within analysis-day(s). Coaches were allowed to watch the plays as many times as necessary, to increase the precision of their judgment regarding the SPD they were asked to assign to each action indicated for analysis in the video-clips. Once again, researchers applied the Kappa test and, similarly to the previous time, the variable submitted to analysis was the SPD assigned to the action indicated in the video-clip for the analysis. Only SPDs with Kappa coefficients $\geq .85$ of concordance between coaches were maintained and resulted in the final set of SPDs. Table 1 displays the obtained SPDs for offense versus defense interactions involving $1 \times 1$, $2 \times 2$ and $3 \times 3$ situations.

Table 1. SPD classes for offense versus defense interactions involving $1 \times 1,2 \times 2$ and $3 \times 3$ players.

\section{SPD for $1 \mathrm{x} 1$ situations in the Perimeter (non-ordered categories)}

\subsection{Oriented}

1.1.1 Baseline: There is a strategic preferential side for the penetration of the attacker. The defender orients the attacker to baseline. Defender's body rotation and feet direction are diagonally blocking the progression of the attacker to the middle toward the basket.

1.1.2 Middle: There is a strategic preferential side for the penetration of the attacker. The defender orients the attacker toward the middle of the court. Defender's body rotation and feet direction are diagonally blocking the progression of the attacker to the baseline.

1.2 Non-oriented

1.2.1 Neutral: There is not a preferential side for penetration of the attacker. From the top of the key until the wing, the defender keeps his back aligned in parallel with the basket. In the corner area (i.e. after the imaginary free-throw line extended, following to baseline) the body rotation is perpendicular to the basket and the feet orientation is perpendicular to the three points line.

\section{SPDs for $2 \times 2$ situations in the Post}

\subsection{Defense of the Passer - Before the entry pass}

\subsubsection{Oriented}

2.1.1.1 Baseline: There is a strategic preferential side for the penetration of the attacker. The defender orients the attacker to baseline. Defender's body rotation and feet direction are diagonally blocking the progression of the attacker to the middle toward the basket.

2.1.1.2 Middle: There is a strategic preferential side for the penetration of the attacker. The defender orients the attacker to the middle of the court. Defender's body rotation and feet direction are diagonally blocking the progression of the attacker to the baseline and to the key.

2.1.2 Non-oriented

2.1.2.1 Neutral: There is not a preferential side for penetration of the attacker. From the top of the key until the wing, the defender keeps his back always aligned in parallel with the basket. In the corner area (i.e. a polygonal area delimited by: i) an imaginary extension of the free-throw line until the sideline, ii) paint line, iii) baseline, iv) sideline) the body rotation is perpendicular to the basket and the feet orientation is perpendicular to the three points line. 
Table 1 (cont.). SPD classes for offense versus defense interactions involving $1 \times 1,2 \times 2$ and $3 \times 3$ players.

2.2 Defense of the Post Player - Before Entry Pass

2.2.1 Oriented

2.2.1.1 Baseline: Body rotation guarding “ $3 / 4$ ” of the offensive player and blocking baseline displacement or passing line.

2.2.1.2 Middle: Body rotation guarding “ $3 / 4$ ” of the offensive player and blocking penetrations in the middle (painted area) or passing line to the middle.

2.2.2 Non-oriented

2.2.2.1 Neutral: In the front or in the back of the offensive player. The term neutral does not refer to a lack of aggressiveness in the defense but to the absence of a side preference.

2.3 Defense of the Passer - After Entry Pass

2.3.1 Oriented or Non-oriented: Baseline, Middle or Neutral: identical to the criteria of "Defense of the Passer - Before the entry pass" 2.4 Defense of the Post Player - After Entry Pass

2.4.1 Oriented or Non-oriented: Baseline, Middle or Neutral: identical to the criteria of "Defense of the Passer - Before the entry pass" and "Defense of the Passer - After the entry pass"

3. SPD for space creation without the ball situations

3.1 Defense of the Passing Player

3.1.1 Oriented (baseline; middle) or Non-oriented (neutral): identical to the defense of $1 \mathrm{x} 1$ in the perimeter. The same criteria are applied.

3.2 Defense of the Receiver Player (attacker without the ball)

3.2.1 Close: Passing line and displacement trajectory are blocked by the defender.

3.2.2 Away: The defender does not constraint the attacker displacement as a consequence of a help defense or positioning error.

4. SPD for $2 \mathrm{x} 2$ situations of on ball screen

4.1 Defense of the ball player

4.1.1 Second (Fight-thru): Defender passes over the screen with his defensive posture preserved and conserves himself between the attacker and the basket.

4.1.2 Second (Follower): Defender passes over the screen but loses his defensive posture and is either delayed or side-by-side with the attacker in relation to the basket.

4.1.3 Third: Defender of the ball player passes between the screener and the defender of the screener in order to follow the attacker that received the screen.

4.1.4 Fourth (Behind): Defender of the ball player passes behind the defender of the screener in order to follow the attacker that received the screen.

4.1.5 2x1 (Trap): The defender of the ball player and the defender of the screener momentarily guard (i.e. double guard with pressure) the ball player.

4.1.6 Switch: The defender of the ball player and the defender of the screener switch players being guarded.

4.1.7 Deny: The defender of the ball player rotates his body obstructing the attacker's displacement toward the screen set by the screener.

4.2 Defense of the screener player

4.2.1 Vertical show: Defender displacement aligned with the screener' shoulders

4.2.2 Horizontal show: Defender displacement perpendicular to the screener' shoulders

4.2.3 Open: Defender step aside and returns to the proximity of the attacker.

4.2.4 Fluctuate: Defender steps aside and keeps the distance from the screener.

4.2.5 Push: Sustain the position close to the attacker, with physical contact imposing some positional constraint to the screener. 4.2.6 Switch: The defender of the screener and the defender of the ball player switch their positions.

4.2.7 $2 \times 1$ (Trap): The defender of the screener and the defender of the ball player momentarily guard (i.e. double guard with pressure) the ball player.

\section{SPD for $3 \times 3$ situations of out of the ball screen}

\subsection{Defense of the passing player}

5.1.1 Oriented (baseline; middle) or Non-oriented (neutral): identical to the defense of $1 \mathrm{x} 1$ in the perimeter. The same criteria are applied. 
Table 1 (cont.). SPD classes for offense versus defense interactions involving $1 \times 1,2 \times 2$ and $3 \times 3$ players.

5.2 Defense of the screener

5.2.1 Vertical show: Defender displacement aligned with the screener' shoulders.

5.2.2 Open: Defender step aside and returns to the proximity of the attacker.

5.2.3 Fluctuate: Defender step aside and keeps the distance from the screener.

5.2.4 Push: Sustain the position close to the attacker, with physical contact imposing some positional constraint to the screener.

5.2.5 Bump: Defender step aside and briefly attempts to change the trajectory of the screen receiver by performing successive body contacts

5.2.6 Switch: The defender of the screener and the defender of the ball player switch positions.

5.2.7 2x1 (Trap): The defender of the screener and the defender of the ball player momentarily guard (i.e. double guard with pressure) the ball player.

5.3 Defense of the receiver of the screen

5.3.1 Second (Fight-thru): Defender passes over the screen with his defensive posture preserved and staying between the attacker and the basket.

5.3.2 Second (Follower): Defender passes over the screen but loses his defensive posture and is either behind or side-by-side with the attacker in relation to the basket.

5.3.3 Third (Middle): Defender passes between the screener and the defender of the screener in order to follow the attacker that received the screen.

5.3.4 Fourth (Behind): Defender passes behind the defender of the screener in order to follow the attacker that received the screen. 5.3.5 Switch: The defender of the ball player and the defender of the screener switch players being guarded.

5.3.6 Deny: The defender of the ball player rotates his body obstructing the attacker's displacement in direction to the screen set by the screener.

Figure 1 displays diagrams with the SCDs-SPDs couples. Diagrams 1-3: $1 x 1$ interactions in the perimeter, where: 1: neutral; 2: oriented to the middle; 3 : oriented to the baseline; 4-7: $2 \times 2$ interactions in the post, before the entry pass, where: 4: neutral - front; 5: neutral - back; 6:3/4 under; 7: 3/4 over; 8-10: $2 \times 2$ interactions in the post, after the entry pass, where: 8: neutral; 9: oriented to the middle; 10: oriented to the baseline; 11-12: interactions based on the space creation without ball, where: 11: close; 12: away. In this case, the classes of defensive actions for the passer player are the same of 1x1 situations; 13-16: actions for the defender of the ball player in the on ball screen, where: 13w: second (fight-thru), 13x: second (follower), 13y: third (middle), 13z: fourth (under); 14: trap; 15: switch; 16: deny; 17-24: actions of the defender of the screener in the on ball screen, where: 17: vertical show; 18: horizontal show; 19: open; 20: away; 21: sustain; 22: push; 23: switch; 24: trap; 25-27: actions for the defender of the receiver of the out of ball screen, where: 25w: second (fight thru), 25x: second (follower), 25y: third (middle), 25z: fourth (under); 26: switch; 27: deny; 28-34: defender of the screener of the out of ball screen, where: 28 : show; 29: open; 30: away; 31: sustain; 32: push; 33: switch; 34: bump.

Sixth, a pilot study was designed to apply the final version of the SPDs. In this experiment, matches from tournaments involving different age groups, sex and competition level were analyzed to check the generality of the conceived classes to describe the defensive actions performed in the match. Seventh, the SPDs conjointly with the SCDs were applied to infer strategy characteristics of high-level basketball teams.
The next sub-section describes the experiment for strategy inference.

\section{Application to match analysis}

\section{Sample}

The resultant SCD-SPD couples were applied to match analysis. The sample was comprised of six consecutive matches from the same team (Barcelona F.C.), in the same tournament (Liga ACB - Spanish championship, 2010-2011), against semi-final and final adversaries (i.e., Caja Laboral and Bilbao Biskaia).

In a ball possession, the match analyst annotated the event every time that a SCD-SPD couple occurred. Actions not related to creating space or protecting space (e.g., standing, walking) were not considered for analysis. The analysis of the matches took in consideration the following variables: i) teams involved and competition phase (i.e. semi-final or final); ii) SCD; iii) SPD; iv) SCD-SPD interaction patterns. The playoff system is appropriate to investigate the recurrence of tactical patterns as Barcelona confronted both Caja Laboral and Bilbao Biskaia three times in a row. This competition system increases the probability of occurrence of each of the SCD-SPD couples and enables the identification of changes in strategy when playing against a different opponent (i.e., playoff winner).

Analysis considered the frequency of SCD-SPD couples of actions along a ball possession for each team against each 


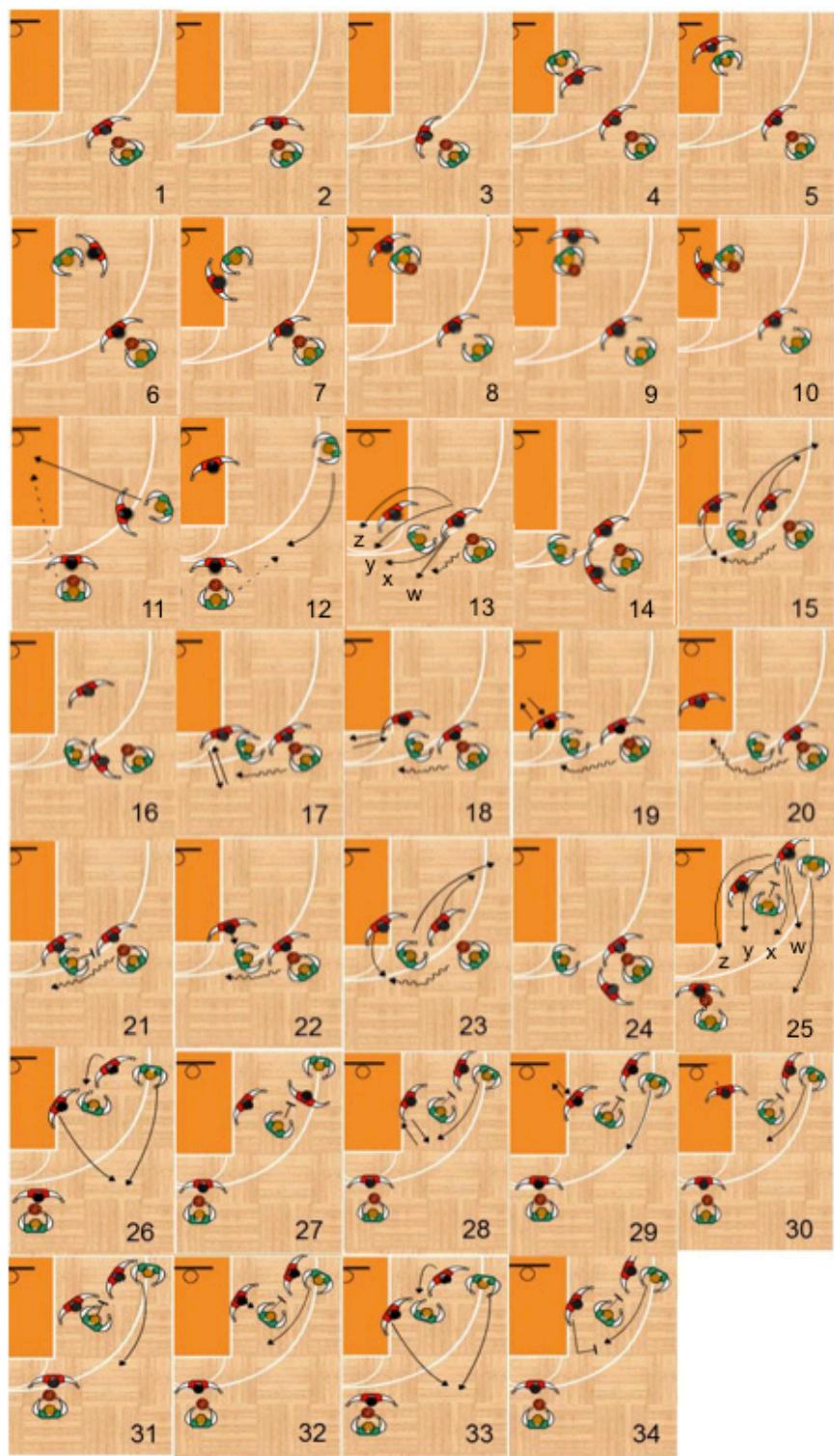

Figure 1. Basketball court diagrams with patterns of SCDs-SPDs couples in $1 \times 1,2 \times 2$ and $3 \times 3$ interactions, where: continuous arrows: displacements without ball; zigzag arrows: displacements with ball; dotted arrows: pass action; T-shape straight line: screen. In diagrams 13 and 25: 'w': follow thru; ' $x$ ': follower; ' $y$ ': third; ' $z$ ': fourth.

adversary. This information was used to evaluate strategic trends of teams regarding the number of SCD-SPD couples performed in a ball possession and the diversity of SCD and SPD classes observed. Related outcomes to the sequences of SCD-SPD couples were defined as follow: i) space created offense is able to disrupt the defense and create an adequate situation to score; ii) space protected - defense contains the offense and keeps an adequate positioning to protect the basket; iii) delay - defense has a dynamical disadvantage in relation to the offense, leading to a non-optimal defensive positioning, but is able to perform partial contestation of the offensive action. Inter-raters reliability of the defining criteria of each outcome category was assessed by the researchers, previously to its use in the experiment, with a sample of 50 ball possessions from different basketball matches. In this experiment, complete agreement was found. Frequencies of SCD-SPD couples and the respective outcomes were manually annotated based on visual observation of videos of the matches. Finally, the specific SCDs-SPDs with greatest frequency were discriminated. Spanish professional league appeared to favor the assessment of the recurrence of SCD-SPD couples as its teams are recognized by their collective organization and adherence to the team strategy.

\section{Data analysis}

Data analysis comprehended three stages. In the first stage, it was evaluated the number of concatenated SCD-SPD couples in a ball possession. A SCD-SPD concatenation occurred every time a SCD-SPD couple was followed by another one without discontinuing or interrupting the offensive actions. SCD-SPD concatenation defined a measure of the interactions length ${ }^{5}$ in a ball possession. For this purpose, a specific notational syntax was developed in which pairs of numbers represented the length of the employed SCD-SPD couples. The first number indicates the first SCD-SPD couple and the second number specifies the number of concatenated couples. For instance, a ball possession had two concatenated SCD-SPD couples. Then, number 1 was annotated for the first SCD-SPD couple, and the second number 1 was assigned for the concatenated subsequent couple (i.e., ' 11 ', one and one). In the case of three concatenated actions, the notation would be ' 12 ' (i.e., first SCD-SPD couple and two concatenated ones), and so on. If there were two or more non-concatenated SCD-SPD couples in an offense, new couples would be annotated. For example, '101010' were annotated to assign three independent SCD-SPD couples in a given ball possession. In the second stage, the outcomes related to the concatenations of SCDs-SPDs were considered. Finally, in the third stage, the proportions of SCDs-SPDs for the most recurrent interaction patterns were summarized.

\section{Statistical analysis}

The calculation of Kappa coefficient enabled the analysis of the expert judges' annotations of SPDs in two different moments of the validation process. First, it was used to estimate the agreement within high-level coaches and between high-level coaches and the researchers regarding the SPDs defining criteria. In a second moment, with the established criteria, Kappa coefficient was applied to determine intra- and inter-rater reliability scores of the ability of the second set of specialists to classify SPDs. In this second case, intra- and inter-observer rates were estimated between and within days. Researchers used $\mathrm{SAS}^{\circledR} 9.2$ for all of the statistical analyzes.

\footnotetext{
${ }^{5}$ Herein, length comprehends the extension of a sequence of offense-defense interactions, in terms of the number of SCD-SPD pairs combined in the sequence.
} 


\section{Results}

\section{Intra and inter-rater reliability test}

Table 2 displays the results of intra- and inter-rater reliability tests for checking the SPDs criteria described in the fifth stage of the validation process with the second set of high-level basketball coaches. The Kappa level of agreement was greater than .88 indicating an almost perfect intra- and inter-rater agreement (Landis \& Koch, 1977) by the end of the criteria refinement. Moreover, symmetry test of the Kappa values indicated no differences within and between ratios in the identification of the SPDs $(p>.05)$.

Table 2. Reliability ratios for inter- and intra-observers. Where for each intra-observer comparison: first rate: time1 versus time2; second rate: time 1 versus time3; third rate: time 2 versus time 3.

\begin{tabular}{lccc}
\hline & Observer 1 & Observer 2 & Observer 3 \\
\hline Observer 1 & $.96 / .92 / .96$ & .89 & .90 \\
Observer 2 & .89 & $.95 / .93 / .95$ & .92 \\
Observer 3 & .90 & .92 & $.95 / .96 / .97$ \\
\hline
\end{tabular}

\section{Application to match analysis}

Short sequences of concatenated SCD-SPDs (i.e., 10 and 11) were more frequent than longer ones (i.e., 12; 1010; 101010), among teams and competition phases (Table 3 ). Sequences with no re-start of the offense (e.g., 10,11) represented $71 \%$ of the total SCD-SPDs couples, for all of the teams. A single re-start (e.g., 1010, 1111) occurred in 18\% of the offenses, whilst sequences with two and three re-starts corresponded to $3 \%$ and $2 \%$, respectively. Sequences with four re-starts presented a very low frequency of occurrence (i.e., $.5 \%$ ).

Table 3. SCD-SPD sequence lengths in the semi-final and final series, where: first, third and fifth numbers in the sequence indicate the beginning of a new action. Second, fourth and sixth numbers indicate the subsequent concatenated actions in regards to the action indicated in the previous number. Sequence length: SL; percentage: \%; space created: SC; delay: D; space protected: SP.

\begin{tabular}{|c|c|c|c|c|c|c|c|c|c|}
\hline \multicolumn{10}{|c|}{ Semifinals } \\
\hline \multicolumn{5}{|c|}{ Barcelona } & \multicolumn{5}{|c|}{ Caja Laboral } \\
\hline SL & $\%$ & $\mathrm{SC}$ & D & SP & SL & $\%$ & SC & D & SP \\
\hline 10 & 47 & 33 & 35 & 32 & 10 & 52 & 22 & 43 & 35 \\
\hline 11 & 27 & 42 & 49 & 9 & 11 & 18 & 27 & 63 & 10 \\
\hline 1010 & 8 & 18 & 44 & 38 & 1010 & 13 & 23 & 30 & 47 \\
\hline 12 & 5 & 10 & 60 & 30 & 101010 & 5 & 0 & 50 & 50 \\
\hline \multicolumn{10}{|c|}{ Finals } \\
\hline \multicolumn{5}{|c|}{ Barcelona } & \multicolumn{5}{|c|}{ Bilbao Biskaia } \\
\hline SL & $\%$ & SC & D & SP & SL & $\%$ & SC & D & SP \\
\hline 10 & 50 & 36 & 30 & 34 & 10 & 51 & 35 & 27 & 38 \\
\hline 11 & 21 & 23 & 50 & 27 & 11 & 19 & 17 & 48 & 35 \\
\hline 1010 & 7 & 18 & 44 & 38 & 1010 & 11 & 19 & 27 & 54 \\
\hline 12 & 5 & 17 & 50 & 33 & 12 & 5 & 18 & 37 & 45 \\
\hline
\end{tabular}

In regard of the interaction outcomes, assuming both space created and delays as positive offensive outcomes, offensive success overcame defensive success for all of the sequence lengths presented. Specifically, 10 and 11 sequences produced more space created outcomes than other sequences with greater lengths. The length of the sequence did not affect the occurrence of delays, while long sequences seemed to favor space protection conditions.

Table 4 presents the two most frequent patterns of sequence length described above (i.e., 10 and 11 ), the related SCD-SPD interaction contents and their respective relative frequencies. For both 10 and 11 lengths, the table displays the results only for interaction patterns with frequencies greater than $5 \%$ for each sequence length. Lower frequencies indicate rare events, whose execution may be consequence of occasional contingencies of confront and, consequently, not relevant for unraveling strategic features of the team.

Table 4. SCDs-SPDs for the two most recurrent interaction patterns (i.e., ' 10 ' and ' 11 ') for all teams in both semi- and final phases. Values expressed in percentage (\%) relative to the interaction sequence length.

\begin{tabular}{|c|c|}
\hline \multicolumn{2}{|r|}{ Semifinals } \\
\hline & Barcelona \\
\hline 10 & $\begin{array}{l}\text { on ball screen }- \text { second }+ \text { away }(14 \%) ; \text { ball dribbling-oriented } \\
(14 \%) ; \text { ball dribbling }- \text { not oriented }(13 \%) \text {; on ball screen }- \\
\text { second }+ \text { show }(8 \%) ; \text { without ball }- \text { fluctuation }(6 \%)\end{array}$ \\
\hline 11 & $\begin{array}{l}{[\text { ball dribbling }- \text { not oriented; without ball }- \text { fluctuation }](12 \%) \text {; }} \\
{[\text { On ball screen }- \text { second }+ \text { show; without ball }- \text { fluctuation }]} \\
(10 \%) ;[\text { on ball screen }- \text { second }+ \text { away; without ball }- \text { fluc- } \\
\text { tuation }](7 \%)\end{array}$ \\
\hline
\end{tabular}

Caja Laboral

10 on ball screen - second + away (12\%); ball dribbling - not oriented (12\%); ball dribbling-oriented ( $9 \%)$; on ball screenswitch + switch (6\%); out of ball screen - second + away $(6 \%)$

11 [out of ball screen - second + sustain; on ball screen-second + away] (10\%); [on ball screen - second + away; on ball screen-second + away $](8 \%) ;[$ on ball screen - third + away; on ball screen - second + away $](8 \%)$

\begin{tabular}{c}
\hline Finals \\
\hline Barcelona
\end{tabular}

10 ball dribbling - oriented (12\%); ball dribbling - not oriented (11\%); on ball screen - second + away (7\%); out of ball screen - second + sustain $(7 \%)$

11 [on ball screen-second + show; without ball-out of position] (8\%); [out of ball screen - second + sustain; ball dribbling oriented] (8\%); [ball dribbling - not oriented; without ball - fluctuation] $(6 \%)$

\begin{tabular}{|c|c|}
\hline \multicolumn{2}{|r|}{ Bilbao Biskaia } \\
\hline 10 & $\begin{array}{l}\text { ball dribbling }- \text { not oriented }(15 \%) ; \text { ball dribbling oriented } \\
(14 \%) ; \text { out of ball screen }- \text { second }+ \text { sustain }(10 \%) ; \text { on ball } \\
\text { screen }- \text { second }+ \text { away }(7 \%)\end{array}$ \\
\hline 11 & $\begin{array}{l}\text { [ball dribbling-oriented; without ball-out of position] }(14 \%) ; \\
{[\text { on ball screen }- \text { second }+ \text { show; without ball }- \text { fluctuation }} \\
(12 \%) ;[\text { on ball screen }- \text { second }+ \text { away; without ball }- \text { out of } \\
\text { position }](7 \%) ;[\text { out of ball screen }- \text { second }+ \text { sustain; without } \\
\text { ball }- \text { fluctuation }](7 \%)\end{array}$ \\
\hline
\end{tabular}


In sequences of 10 length, three patterns were more frequent for all of the teams: i) ball dribbling-oriented; ii) ball dribbling - not oriented; and iii) on ball screen-second + away. There is a great variety of possible SPD combinations for the defense of the on ball screen and the recurrence of on ball screen-second + away indicates a consistent pattern of interaction for this $2 \times 2$ situation. In sequences of 11 length, two other patterns presented high frequencies of occurrence: i) sequences initiated with on ball screen actions, mainly defended by "second + away"; ii) concatenation of a first offensive action with a space creation without ball or another on ball screen.

In an offensive perspective, Barcelona performed on ball screens on $22 \%$ of the actions in pattern 10 during the semifinals. Moreover, pattern 11 was initiated with an on ball screen on $17 \%$ of the occasions. On the other hand, during the finals, on ball screen corresponded to only $7 \%$ of the actions in pattern 10. Pattern 11 was initiated with on ball screen on $16 \%$ of the occasions.

\section{Discussion}

The aims of the present study were to validate a set of SPDs and to analyze matches based on SCD-SPD couples. SPDs were successfully created and validated based on well-defined criteria and high agreement scores. After validated, the SPDs together with the SCDs (i.e., SCDs-SPDs couples) enabled to identify offense-defense interaction patterns in basketball games of the Spanish professional league. The analyzes of the interactions revealed that short sequences were more frequent than long ones. Additionally, the most recurrent concatenated patterns were similar among teams whilst less frequent concatenation patterns presented a great diversity among teams.

\section{SPDs validation}

Validation of the SPDs followed the procedures described by Lamas et al. (2011), while reliability procedures followed James, Taylor, and Stanley (2002) and O'Donoghue (2007) recommendations. The criteria applied to define each SPD were exhaustively tested (Table 1) and the intra- and inter-rater reliability scores revealed high accuracy in distinguishing the classes (Table 2). Accordingly, the intra- and inter-rater reliability ranged between $.92-.97$ and $.88-.97$, respectively (Landis \& Koch, 1977).

The SPDs developed herein are a logical complement to the previously defined SCDs in (Lamas et al., 2011) because Lamas and colleagues did not consider a fundamental element to the analysis of tactical patterns, the adversary's defense. Hence, the present work introduces a more discriminative approach to the investigation of interaction patterns than the previous one, which can be generalized to other team sports. Based on this approach, researchers can assess not only the tactical patterns of both teams but also the possible influence of the obtained outcomes on the frequency of occurrence of the tactical patterns.
Indeed, interaction patterns in team sports have been previously investigated in a different perspective (Vilar, Araujo, Davids, \& Button, 2012), in which the formation of playing patterns was analyzed through the dynamics of both single (Correia et al., 2012; Esteves et al., 2012) and multiple offensive-defensive couples of players (Corrêa, Vilar, Davids, \& Renshaw, 2012; Duarte et al., 2012). In these studies, the assessment of offense-defense dynamics was used as a framework to determine players' decision process. Both approaches to interaction patterns seem to be complementary, as SCD-SPD couples represent a framework regarding the technical-tactical meaning of the interaction behaviors for a specific sport in which spatiotemporal dynamics are worth to be further investigated to depict the patterns of play among players with greater contribution for offensive or defensive success.

For instance, the results of the present study reinforced that on ball screen and second+away are highly recurrent behavioral patterns in basketball offense and defense, respectively (Table 4). This SPD characterizes a defensive alternative that imposes very limited space to the ball player displacement, in which the defender tries to stay as close as possible to him and, at the same time, the defender of the screener stays away from the screen with the aim of protecting the area closer to the basket as the screener often displaces in that direction, after the screen. When this action is well concatenated by the two defenders, it neutralizes the offensive action and forces the offense to plan another play. Nonetheless, the concatenation of actions between team players, or even the concatenation established in relation to the adversary, involves several subtle regulatory processes. Thus, to investigate offense-defense interaction patterns gathering the approaches of classes of actions and its inherent dynamics may represent an auspicious framework. Classes of actions (i.e., SCD-SPD couples) may define an observational set-up in which the success or failure of a single player or a group of players can be interpreted by a set of variables sensitive to the players' dynamics.

The highly diverse defensive alternatives (Table 1) are compatible with progressively more complex defensive strategies with specific actions planned to respond to particular offensive behaviors. The approach provided by the SCD-SPD couples allows differentiating strategic behaviors (i.e., previously planned) from those that emerge during the match. Behaviors with higher frequencies of occurrence may be related to the strategy of the teams. Moreover, the analysis of SCD-SPD couples helps to explain the causative processes that affect the outcomes. This analysis is supported by the literature, which reinforces the importance of shifting from a discrete action analysis to a continuous goal-directed behavior analysis (Correia et al., 2013; Glazier, 2010; McGarry, 2009). A possible limitation of the methodology is that to accomplish demands of describing the actions' semantics, it necessarily requires the identification of specialized tactical patterns (e.g., SCDs and SPDs, such as an on ball screen) in the midst of several events in a match. It may remain a challenge for analysts not specialized in basketball. 


\section{Dynamical analysis of interaction patterns}

Lengthwise, the most frequent interaction patterns of the SCDs-SPDs couples in the annotated sequences were very similar among teams, and the sequences presented a small number of concatenated SCDs-SPDs couples (Table 3). On average, 10 and 11 sequences accounted for $71.2 \%$ of the interaction patterns, on each confront. Yet, 1010 and 12 sequences occurred in Barcelona and Bilbao Biskaia matches, while Caja Laboral presented the pattern 101010, instead of 12 . However, these patterns accounted for only $\sim 15 \%$ of the interaction patterns on each confront.

Spanish basketball teams seems to have highly elaborated strategies, which would lead to longer offensive interactions until one of the teams can overcome the adversary. However, the present findings do not support this empirical notion as short sequences of offensive-defensive interactions were predominant. A possible explanation for these findings relates to the defensive improvement in basketball teams. As a consequence of defensive development, teams have become more efficient in moving the offense away from the location in which the attackers planned to perform the SCDs. Therefore, the concatenation of two offensive actions (i.e., interaction patterns 11) was frequent and successful (on average, $21 \%$ of total frequency of length patterns; $40 \%$ of space created and delays generated). However, longer sequences than 11 seem to be neutralized by defense, as indicated by the considerably lower frequency of 12 pattern (5\%, on average).

In sequences as $1010(10 \%$, on average), the third most frequent, there is a re-set of the offense between interactions, indicating defensive capability to protect the basket. The lower recurrence of these actions is aligned with the previous idea that the offensive team struggles to get in the appropriate position to run the offense. Furthermore, if the first trial is not well succeeded, the offense may not have enough time for a second attempt. Longer sequences than 1010 had frequencies of occurrence $<3 \%$ of the total of the patterns. Hence, the analysis of the interactions considering both teams unraveled that the actions of space creation and protection were short in length.

Offensively, Barcelona F.C., the team analyzed against two different adversaries, presented distinct frequencies of SCDs between playoff series (e.g., on ball screen, in the semifinals (finals), corresponded to: $22 \%(7 \%)$ of the actions in pattern 10 and $17 \%(16 \%)$ of the actions in pattern 11 . It suggests that the methodological approach herein applied was sensitive enough to capture the strategic adjustments performed by a team to play against each of the adversaries. Defensively, teams presented few preferential defensive actions, despite the great number of possible SPD patterns (Table 4). Indeed, in the semi-finals Barcelona defended Caja Laboral's on ball screen mainly with: i) second + away; ii) switch + switch. Additionally, it defended the out of ball screen with: i) second + away. In the finals, Barcelona defended Bilbao Biskaia on ball screen mainly with: i) second + away. However, there was a modification in the most frequent SPD to defend out of ball screen, performing the second + sustain (data not shown). Unfortunately, there is a paucity of data in the literature to enable comparisons.
The diversity of interaction patterns was higher for long sequences (e.g., 12,13,1211), which may have occurred due to the fact that during the sequence of interactions the adherence to the strategy may progressively decrease. The observed actions result from both the attempt to execute the strategy and the constraints imposed by the adversary, leading to several unpredictable adjustments based on the emergent situations in the confront. In cases when sequences are intermediated by a re-start of the offense, for instance 1010, patterns were similar to those found in 10 , which indicates the preference to perform according to team's strategy, as another planned action can be executed in the second part of the sequence (i.e., non-concatenated). For instance, (on ball screen - second + away_ball dribbling - not oriented) had a proportion of $25 \%$ for 1010 , corroborating the data found in 10 that on ball screen and ball dribbling were the preferred SCDs to start the offense. The offensive prevalence of on ball screen and ball dribbling, which corroborates with Lamas et al. (2011), suggests a strategic trend of inducing the execution of SCDs that can produce at least short defensive delays, which can be enough to create scoring opportunities.

Sequences of actions 10 and 11 presented high success rates in creating space either by unequivocally creating space or producing a delay for all of the teams analyzed. The occurrence of a second action concatenated with the first (i.e., 11) seemed to have a positive impact on offense success, especially in the semifinals. Barcelona and Caja Laboral presented $91 \%$ and $90 \%$ of success in 11 actions, respectively, whilst $68 \%$ and $65 \%$ in 10 actions. In the finals, the values did not follow the same pattern as Barcelona and Bilbao Biskaia presented $66 \%$ and $62 \%$ of success in 10 and $73 \%$ and $65 \%$ in 11 actions, respectively. Sequences with longer concatenations (e.g., 12, 13) did not differ in terms of the obtained positive outcomes. Even though concatenations seem to be beneficial for offense as they allow to progressively increasing the space created, defense may also be able to recover, to reestablish its organization.

In conclusion, the analysis of offense-defense interaction, instead of the actions of a single team, may add relevant information for interpreting teams playing features and outcomes achieved. Although applied to basketball, both contributions presented (i.e., SPDs and SCDs-SPDs couples) may be generalized and used to investigate other team sports.

\section{References}

Collet, C. (2013). The possession game? A comparative analysis of ball retention and team success in European and international football, 2007-2010. Journal of Sports Sciences, 31, 123-136.

Corrêa, U.C., Vilar, L., Davids, K., \& Renshaw, I. (2012). Informational constraints on the emergence of passing direction in the team sport of futsal. European Journal of Sports Sciences, 6, 1-8.

Correia, V., Araújo, D., Duarte, R., Travassos, B., Passos, P., \& Davids, K. (2012). Changes in practice task constraints shape decision -making behaviours of team games players Journal of Science and Medicine in Sport, 15, 244-249.

Correia, V., Araújo, D., Vilar, L., \& Davids, K. (2013). From recording discrete actions to studying continuous goal-directed behaviours in team sports. Journal of Sports Sciences, 31, 546-553. 
Duarte, R., Araújo, D., Freire, L., Folgado, H., Fernandes, O. ,\& Davids, K. (2012). Intra- and inter-group coordination patterns reveal collective behaviors of football players near the scoring zone. Human Movement Science, 31, 1639-1651.

Esteves, P.T., Araújo, D., Davids, K., Vilar, L., Travassos, B., \& Esteves, C. (2012). Interpersonal dynamics and relative positioning to scoring target of performers in $1 \mathrm{vs} .1$ sub-phases of team sports. Journal of Sports Sciences, 30, 1285-1293.

Fonseca, R.P., Salles, J.F., \& Parente, M.A.M.P. (2008). Development and content validity of the Brazilian Brief Neurophysiological Assessment Battery Neupsilin. Psychology and Neuroscience, 1, 55-62.

Glazier, P.S. (2010). Game, Set and Match? Substantive Issues and Future Directions in Performance Analysis. Sports Medicine, 40, 625-634.

Grehaigne, J.F., \& Caty, D.G.P. (2010). Modelling ball circulation in invasion team sports: a way to promote learning games through understanding. Physical Education and Sport Pedagogy, 15, 257-270.

James, N., Taylor, J., \& Stanley, S. (2002). Reliability procedures for categorical data in performance analysis. International Journal of Performance Analysis in Sport, 7, 1-11.

Lamas, L., Barrera, J., Otranto, G., \& Ugrinowitsch, C. (2014). Invasion team sports: strategy and match modeling International Journal of Performance Analysis in Sport, 14, 307-329.

Lamas, L., De Rose Jr., D., Santana, F., Rostaiser, E., Negretti, L., \& Ugrinowitsch, C. (2011). Space creation dynamics in basketball offence: validation and evaluation of elite teams International Journal of Performance Analysis in Sports, 11, 71-84.

Landis, J.R. \& Koch, G.G. (1977). The measurement of observer agreement for categorical data. Biometrics, 33, 159-174.

McGarry, T. (2009). Applied and theoretical perspectives of performance analysis in sport: scientific issues and challenges. International Journal of Performance Analysis in Sports, 9, 128-140.

O'Donoghue, P. (2007). Reliability Issues in Performance Analyis. International Journal of Performance Analysis in Sports, 7, 20-27.

Pfeiffer, M., \& Perl, J. (2006). Analysis of tactical structures in team handball by means of artificial neural networks. International Journal of Computer Science in Sport, 5, 4-14.

Seabra, A., \& Dantas, L. E. P. B. T. (2006). Space definition for match analysis in soccer International Journal of Performance Analysis in Sports, 6, 97-113.

Vilar, L., Araujo, D., Davids, K. \& Button, C. (2012). The role of ecological dynamics in analysing performance in team sports. Sports Medicine, 42, 1-10.

\section{Authors' note}

Felipe L. Santana and Carlos Ugrinowitsch are affiliated with the School of Physical Education and Sport, University of São Paulo. Av. Professor Mello Moraes, n. 65, Cidade Universitaria. Sao Paulo, 05508-030, SP, Brazil.
Eduardo Rostaiser is affiliated with the German Sport University Cologne. Am Sportpark Müngersdorf, n. 6., Cologne, 50933, Germany.

Eran Sherzer is affilaited with the Clube Atlético Paulistano, Rua Honduras, n. 1400, São Paulo, 01428-900, SP, Brazil.

Junior Barrera is affiliated with the Institute of Mathematics and Statistics, University of São Paulo. Rua do Matão, n. 1010, Cidade Universitaria. São Paulo, 05508-090, SP, Brazil.

Leonardo Lamas is affiliated with the Faculty of Physical Education, University of Brasília. Campus Darcy Ribeiro, Asa Norte, Brasília, 70910-970, DF, Brazil.

\section{Acknowledgements}

LL was supported by Fundação de Amparo à Pesquisa do Estado de São Paulo, grant: 2012/19164-0. CU is supported by Conselho Nacional de Pesquisa, grant 304205/2011-7. JB is supported by Conselho Nacional de Pesquisa, grant: 306442/2011-6.

\section{Corresponding author}

Leonardo Lamas

University of Brasilia, Campus Darcy Ribeiro, Asa Norte, Brasília (DF), Brazil, 70910-970

email: 1lamas@unb.br; phone: 00-55-61-31072510

Manuscript submitted on January 28, 2014

Manuscript accepted on on January 24, 2015

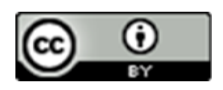

Motriz. The Journal of Physical Education. UNESP. Rio Claro, SP, Brazil - eISSN: 1980-6574 - under a license Creative Commons - Version 3.0 